\title{
NASA Headquarters Space Operations Center: Providing Situational Awareness for Spaceflight Contingency Response
}

\author{
Theresa G. Maxwell ${ }^{1}$ and William J. Bihner ${ }^{2}$ \\ NASA Headquarters, Washington, DC, 20546, USA
}

\begin{abstract}
This paper discusses the NASA Headquarters mishap response process for the Space Shuttle and International Space Station programs, and how the process has evolved based on lessons learned from the Space Shuttle Challenger and Columbia accidents. It also describes the NASA Headquarters Space Operations Center (SOC) and its special role in facilitating senior management's overall situational awareness of critical spaceflight operations, before, during, and after a mishap, to ensure a timely and effective contingency response.
\end{abstract}

\section{Introduction}

Spaceflight is a risky business. Although every reasonable effort is made to ensure the safety of space vehicles and their crews, there is always some residual risk of a mishap, so contingency plans and capabilities are established to assist in the recovery from a space operations mishap. Senior managers at the National Aeronautics and Space Administration (NASA) Headquarters will be heavily involved in the response to serious mishaps involving the Space Shuttle Program (SSP) or the International Space Station (ISS), as they were for Space Shuttles Challenger in 1986 and Columbia in 2003.

Following the Space Shuttle Challenger and Columbia accidents, the Roger's Commission and the Columbia Accident Investigation Board, respectively, were chartered to determine the technical and organizational deficiencies responsible for these disasters. The media closely followed their day to day activities, meeting the public's demand for information and answers. Public interest fostered an environment where accident investigations were conducted openly, thoroughly and with a keen sense of urgency.

Numerous books and papers have been written about the dynamics and processes used in these investigations and the deliberations leading to the development of specific recommendations. It is not the intent of this paper to repeat those events. Rather, the focus of this paper will be to briefly describe the following three topics: first, to describe how NASA labored to find a process to respond to high-visibility accidents in the post-Challenger era; second, to outline the process NASA used to track and document implementation of the Columbia Accident Investigation Board recommendations; and finally, to describe how NASA Headquarters managers used the lessons of Challenger and Columbia to become an organization intent on maintaining a heightened awareness of every aspect of today's complex and inherently risky Space Shuttle and ISS mission activities.

Section II provides an overview of the NASA Headquarters mishap response process, and describes how it evolved from the beginning of the Space Shuttle program based on the Challenger accident. Section III identifies key lessons learned while implementing the contingency response process following the Columbia accident. And lastly, Section IV describes the Headquarters Space Operations Center (SOC) and its role in providing situational awareness to support senior management before, during, and after a mishap.

This paper only addresses the NASA mishap response and contingency declaration process as it relates to space operations missions under the purview of the NASA Space Operations Mission Directorate (SOMD), specifically the SSP, the ISS Program (ISSP), and the Launch Services Program (unmanned launches with NASA payloads). The paper does not address contingency plans and processes that may exist for other NASA space programs.

\section{Headquarters Mishap Response Process}

The NASA Headquarters Space Shuttle Headquarters Office has been the long-standing responsible office for maintaining a contingency response plan or Contingency Action Plan (CAP). In the early post-Apollo era, prior to

\footnotetext{
International Space Station Office, Space Operations Mission Directorate, 300 E Street SW, mail code: CJ000

${ }^{2}$ Space Shuttle Program Office, Space Operations Mission Directorate, 300 E Street SW, mail code: CK000.
} 
the first Space Shuttle fight (STS-1 on April 12-14, 1981), the CAP addressed specific roles and responsibilities for Headquarters offices and NASA Field Centers involved in SSP processing and flight activities. Even the early CAP's outlined a process for identifying and responding to SSP-related mishaps. The appointment of a Mishap Investigation Board was the responsibility of the Associate Administrator for Space Transportation Systems (AA/STS) in consultation with the Administrator and the NASA Chief Safety Officer's concurrence. The mishap boards were supported by a number of working groups, identified in the CAP, and in general located at the Field Centers. The Working Group chairs were appointed at the time of the mishap, from NASA Field Center personnel resources. The eleven initial Working Groups included:

1) Records and Witnesses

2) Fire, Explosives \& Radiological

3) Launch, Landing \& Retricval Operations

4) Facilities \& Ground Support

5) Flight Vehicle Systems \& Performance

6) Payloads

7) Flight Operations \& Network

8) Flight Crew

9) Procedures Review

10) Public Affairs

11) Secretariat

It is interesting to note that in the CAP's published prior to the first Space Shuttle flight, the CAP's "effectivity" was defined to support just the Space Shuttle's Orbital Flight Test Program. ("EFFECTIVITY. This plan is effective immediately and will remain in effect through completion of the Orbital Flight Test Program.") The reference to the Orbital Flight Test Program may have been a reference to the first four "test" flights of the Space Shuttle, after which time it was envisioned that the Space Shuttle vehicle would become a fully "operational" system. However, a CAP document not only continued well beyond the Space Shuttle's Orbital Flight Test Program, but kept intact the early definitions, the roles and responsibilities, and the use of Working Groups to support mishaps. Only slight changes to the Working Group structure, but not their functionality, occurred over the years leading to the Challenger accident.

\section{A. How the Process was influenced by the Challenger Accident}

When the Challenger accident occurred, NASA convened a Mishap Investigation Board, following the guidelines of the CAP. When NASA leamed that a Presidential Commission was being formed to investigate the accident, NASA opted to put the mishap board's activities on hold until the Presidential Commission was formed. When the Presidential Commission, or Rogers Commission, began their investigation, NASA disbanded its Mishap Investigation Board.

Post-Challenger, the process of how NASA responded to mishaps changed. NASA came away from the accident with a renewed motivation of not only maintaining an up-to-date CAP but to also be very proactive in its execution. The two most important changes to the CAP supporting this philosophical change were the formation of (1) a Headquarters Contingency Action Team and a (2) Standing Interagency Mishap Investigation Board.

When the Associate Administrator for Space Operations declares a mishap a contingency, the Administrator can authorize the activation of the Headquarters Contingency Action Team (HCAT) to help focus Headquarters capabilities on an accident investigation. This ensures that needed personnel and financial resources are quickly and efficiently applied to the investigation, and the relaying of accident investigation information to NASA's stakeholders is done with a high level of accuracy and consistency. The HCAT membership is pre-identified in the CAP as a group of senior NASA Headquarters managers and includes, as a minimum²:

1) NASA Administrator

2) Deputy Administrator

3) Associate Administrator

4) Chief of Staff

5) Associate Deputy Administrator

6) White House Liaison

7) Assistant Administrator for External Relations

8) Associate Administrator for Space Operations

9) Deputy Associate Administrator for Space Operations

10) Associate Administrator for Institutions and Management

11) Assistant Administrator for Infrastructure 
12) Assistant Administrator for Security \& Program Protection

13) Chief Engineer

14) Chief Safety \& Mission Assurance

15) Assistant Administrator for Public Affairs

16) Assistant Administrator for Legislative \& Intergovernmental Affairs

17) General Counsel

18) Chief Health and Medical Officer

19) Johnson Space Center Technical Authority

The goal was to quickly determine if the mishap was a contingency and if so, to assembly the HCAT and brief them on the available mishap details. This first briefing was referred to as the Mishap Response Teleconference, or MRT. Following the MRT, the HCAT would work on a forward plan for managing the contingency and prepare the first official external notifications to NASA's stake-holders, including the public.

The second major change was the adoption of a Standing Interagency Mishap Investigation Board. The concept for a standing board was proposed in the early 1990s. The idea was "bottom's up" proposed by the two NASA Headquarters staff members responsible for maintaining the "Agency Contingency Action Plan (CAP) for Space Operations" 2 . The concept was based on lessons learned from the Challenger accident investigation. After a thorough internal review, the concept was presented to the White House and approved in late Spring of 1995. The Board was to be comprised of the individuals filling the following federal government positions:

1) U.S. Navy Commander, Naval Safety Center

2) U.S. Air Force Commander, Air Force Flight Test Center

3) U.S. Air Force Commander, Air Force Safety Center (Air Force Chief of Safety)

4) Department of Transportation, National Expert on Aviation Human Factors

5) Federal Aviation Administration, Director of Accident Investigation

6) U.S. Air Force Commander, 14th Air Force

7) NASA Field Center Director (not mission related to the accident)

Once activated, it was envisioned that the Board would be supported by a NASA Task Force. Task Force members would be recommended to the Board Chair by the Associate Administrator for Space Operations, the NASA Chief Safety Officer, and the NASA Chief Engineer. The number and skills of the individuals providing dedicated support as a Task Force member would ultimately be determined by the mishap scenario and size of the Board with Staff.

The June 1995 letter to the initial interagency members filling the above positions asked for their support and explained the rationale and their duties as follows:

"NASA believes that planning for a pre-established accident Investigation Board will allow an investigation of an incident involving serious injury, loss of life, or significant public interest to begin within 72 hours of the mishap. It would also eliminate perception issues that accompany a purely internal NASA investigation. This plan has been approved by the Executive Office of the President."

The Board would use NASA's established support structure of working groups, facilities, and procedures, specified in the contingency action plans, to conduct the investigation. All elements of NASA would respond directly to this Board, providing records, data, and any other administrative or technical support as required by the Board.

The responses to NASA's request for a Standing Interagency Mishap Investigation Board were unanimously ones of endorsement of NASA's initiative to establish such a Board and full support for serving on a Board if the need should ever arise.

\section{B. Today's Contingency Action Plan}

Today's CAP, the Agency Contingency Action Plan for Space Operations, is virtually unchanged from the CAP in place prior to the Columbia accident. The key elements of the CAP are the scope and definition of a Space Operations mishap, the definition of mishap types and the Headquarters roles and responsibilities for mishap management.

\section{Scope and Definition of a Mishap ${ }^{2}$}

The SOMD CAP covers all Space Operations (SO) programs: the SSP, the ISSP, and the Launch Services Program (LSP) (unmanned launches with NASA payloads). The definition of a "Space Operations mishap" has become all encompassing:

An SO mishap is defined here as any mishap, mission failure, or high visibility close call that causes or may cause a major impact to space operations or prevents accomplishment of a primary mission objective involving SOMDcontrolled personnel, hardware, support equipment, or fachities or any personnel, hardware, software, equipment, or 
facilities that have been integrated with SOMD-controlled flight related systems. An SO mishap can involve any SOMD space operations or development program, including suspected mishap situations at contractor facilities and/or government facilities operated under contract."

2. Mishap Types ${ }^{4}$

Mishaps are classified by Type (A, B, C, D, or Close Call), with a Type A mishap being the most severe. The definitions have remained unchanged for many years. Periodically there have been hints that the safety community would like to increase the dollar amounts associated with each Mishap Type in order to maintain a system of multiple categories. Due more to inflation than mishap severity, the trend has been for an increase in Type A mishaps. Listed below is a simplified version of the current mishap definitions:

1) Type A: Total direct cost of mission failure and property damage is $\$ 1,000,000$ or more and injuries or illness result in fatalities or permanent total disabilities.

2) Type B: Total direct cost of mission failure and property damage of at least $\$ 250,000$ but less than $\$ 1,000,000$ and injuries or illness result in permanent partial disabilities.

3) Type C: Total direct cost of mission failure and property damage of at least $\$ 25,000$ but less than $\$ 250,000$ and nonfatal injuries or illness resulting in lost workdays.

4) Type D: Total direct cost of mission failure and property damage of at least $\$ 1,000$ but less than $\$ 25,000$ and any recordable injury or illness.

5) Close Call: An event in which there is no damage or damage less than $\$ 1000$ and no injuries or minor injuries only, but which possesses a potential to cause a mishap.

\section{Roles and Responsibilities ${ }^{2}$}

Each Headquarters organization plays a unique role in supporting a mishap investigation. While each organization has its assigned responsibilities, it should come as no surprise that the synergy of working as a team is the most effective response for a major mishap. The organizations and their responsibilities are summarized below:

1) The Administrator can activate the HCAT to oversee an accident investigation, and may appoint a Senior Agency Official - Washington (SAO-W) to be a liaison with the Administration.

2) The Space Operations Mission Directorate makes the decision to identify a mishap as a contingency, provides initial information to the HCAT members, and recommends Board selection.

3) The Office of Public Affairs manages and coordinates news inquiries.

4) Safety and Mission Assurance provides advice to the Administrator and approval and concurrence as the Board is formed.

5) External Relations assists with ISS Partner notifications and reviews of international agreements.

6) The Office of Legislative and Intergovernmental Affairs assists with notifications to members of Congress and the Administration.

7) The Office of Instiutions \& Management assists with payments for supplies, services and travel.

8) Field Center Directors at Kennedy Space Center, Marshall Space Flight Center, Stennis Space Center, and Johnson Space Center provide mishap information \& implement contingency decisions.

9) SOMD Program Managers take appropriate actions to minimize losses, and preserve evidence, should a mishap occur.

10) The Health and Medical Officer provides medical support to all aspects of the contingency.

11) NASA Contractors are required to report mishaps and participate in investigations.

The NASA Field Centers and Programs also have their own mishap response plans that define their mishap and contingency procedures. In a summary fashion, the relationship between Headquarters and Center responsibilities is shown in Fig. 1. Throughout the various CAP revisions, the role of the Field Centers has remained one of procedures development to ensure timely mishap notification, investigation technical support, and recordkeeping. When a mishap occurs, the responsible Center will be involved with impounding data and the formation of technical Working Groups for mishap investigation support. Headquarters is responsible for defining policies, roles and responsibilities, and reporting requirements/procedures. Headquarters also works with the Centers to conduct periodic CAP program simulations for management training. The focus of these simulations is to address management's response to a mishap, management decisions that needed to be made as a result of the mishap, the role of other government agencies in supporting the mishap, and external notifications. 


\section{Mishap Response Timeline}

When a mishap occurs, the CAP clearly specifies a timeline for activities and decisions leading to the selection of a Mishap Investigation Board (MIB). The organization involved is required to report the mishap to the Associate Administrator for Space Operations within 60 minutes of occurrence. (To facilitate this notification the CAP has a "Sensitive but Unclassified" section, with restricted distribution, that contains telephone numbers for top Government officials, International Partners, and NASA senior management.) From the initial notification to the selection of an MIB is no greater than a 48 hour process. All the key decisions are made within that time period: classifying the mishap as a contingency; activating the HCAT and the standing Interagency Investigation Board; conducting the Mishap Response Teleconference for the HCAT; and preparing the first official external mishap notifications. A timeline of these activities appears in Fig. 2 .

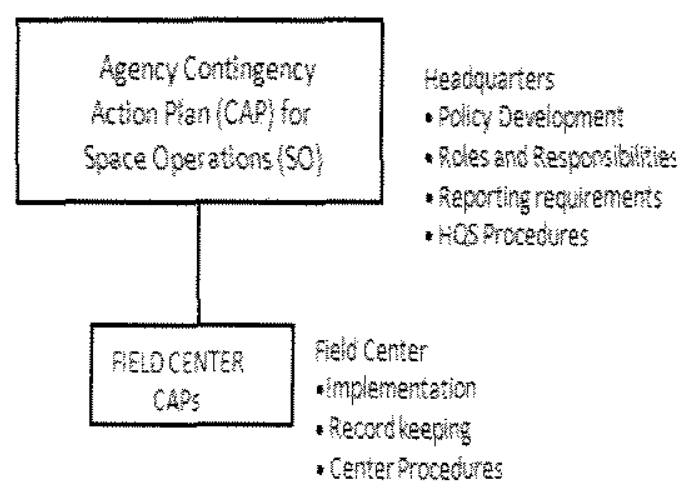

Figure 1. Functional Responsibilities

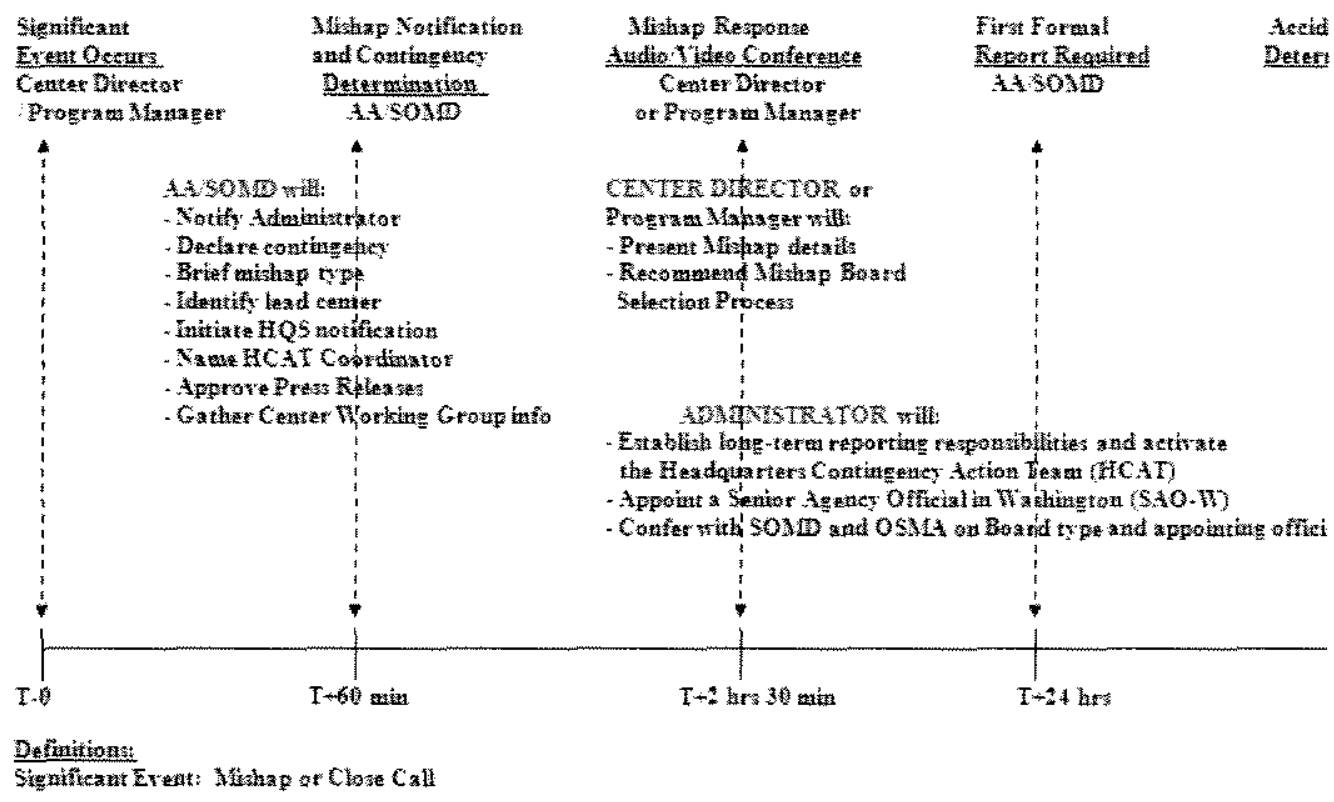

Figure 2. NASA Mishap Activation and Response Timeline

\section{Lessons Learned from the Columbia Accident}

\section{A. NASA's CAP and the Experience of the Columbia Accident - Policy meets Reality}

On February 1, 2003, the Space Shuttle Columbia was beginning its reentry for a planned landing at the Kennedy Space Center's Shuttle Landing Facility at approximately 9:16 AM EST. The deorbit burn maneuver began at approximately 8:15 AM and was executed nominally. In the Johnson Space Center's Mission Control Center (MCC), the reentry appeared nominal until 8:54 AM when 4 hydraulic sensors in the left wing indicated "offscale low." This indication meant that the sensors had falled. At 8:59 AM, the pressure readings on both left main 
landing gear tires were lost. Seconds later, the MCC lost communications with Columbia and shortly after that ground observers made video recordings showing that the Columbia was breaking up on its entry track over Texas. ${ }^{5}$

At NASA Headquarters, the capability to monitor mission activity was limited to local TV news and a handful of mission audio loops. A single employee was monitoring Columbia's reentry that Saturday morning from a small Headquarters conference room. The Associate Administrator for Space Operations, the NASA Chief Safety Officer, and the NASA Administrator were among the first called, shortly after 9:00 AM, when the media began showing video of the Columbia reentry. The decisions to declare a contingency and stand up the HCAT were made immediately.

By 11:00 AM, the HCAT was in place, supported by many other Headquarters employees who came in to help in whatever way they could. The Administrator made a decision to activate the Standing Interagency Mishap Investigation Board. The Administrator and Associate Administrator for Space Operations called the Interagency Board Members and established a teleconference meeting time of 1:00 PM EST.

By 2:00 PM EST, NASA had established the Standing Interagency Mishap Investigation Board, later called the Columbia Accident Investigation Board or CAIB. Following a review of Board member responsibilities, a Mishap Response Teleconference was held to brief the HCAT and Interagency Board on the details of the mishap. Early the next day, the Administrator asked Admiral Harold W. Gehman, Jr. (U.S. Navy, Retired) to be the Board Chairman. The investigation had begun. The CAIB added 5 additional Board members and enlisted a large staff of advisors, technical experts and support staff to manage the data review, the testing associated with finding the primary cause of the accident, and the writing of the Final Report.

Headquarters stood up a 24/7 Return to Flight (RTF) Action Center until the CAIB released its final report in August $2003^{6}$. The task of the Action Center was to maintain awareness of every aspect of the investigation, to organize the efforts of the HCAT, and to ensure the technical accuracy of every press release. To ensure consistency and accuracy, the Headquarters Public Affairs Office issued all NASA press releases related to the Columbia accident.

As the CAIB was releasing its recommendations, NASA formed an independent RTF Task Group to monitor implementation of each CAIB recommendation. Headquarters not only implemented the CAIB recommendations, but also provided the public with a regularly updated account of how the implementation and return to flight were proceeding. The document used for this purpose was the "NASA Implementation Plan for Space Shuttle Return to Flight and Beyond"." This document summarized NASA's implementation of the CAIB recommendations as well as additional, internally-generated activities designed to ensure a safe return to flight. It was published and routinely updated as progress was made in closing actions on the CAIB recommendations. The final edition of the document was released on May 15, 2007, following the second successful RTF mission, STS-121, July 2006.

\section{B. Lessons Learned}

1. The CAP Process Works

When the Columbia accident occurred, was NASA better prepared to handle a major accident than it had been prior to Challenger? To a very great extent, it was. The CAP played out exactly as written. All CAP requirements were followed and resulted in meeting the CAP's goal-oriented timeline (Fig. 2). The verbal and written establishment of an MIB - the Standing Interagency Mishap Investigation Board, was accomplished in less than a day. From a procedural standpoint it could not have happened any more efficiently.

HCAT management of the accident from February 1,2003, through the delivery of the CAIB report, met all expectations. The HCAT stayed engaged in the details of the accident investigation and responded promptly to requests for resources to keep the investigation moving.

The Columbia accident scenario was different than anything imagined in prior mishap simulations. Prior to Columbia, mishap simulations were predominately launch related and assumed a relatively small debris field. For Columbia, the debris field extended from sparsely populated areas southeast of Dallas, Texas, to western Louisiana. With the help of the Federal Emergency Management Agency (FEMA), the Environmental Protection Agency (EPA), and the U.S. Forest Service, a walk-down was organized to search for Orbiter debris (Fig. 3). Eventually, the walk-down included 169 Texas counties and 52 parishes in Louisiana. The search area amounted to 620,999 acres. Included in this area was the 14.48 square mile Toledo Bend Reservoir.

The CAP worked well in getting the mishap investigation started. Once implemented, process changes were made to accommodate the unique circumstances of the Columbia accident. Following Columbia it was thought best to leave any further CAP modifications to be addressed as a function of the mishap details. However, the one strong message from Columbia remained -.- the need for constant vigilance. 
2. The Need for Situational Awareness

Certainly the CAP played a critical role in the proactive response to the Columbia mishap. The significant lesson learned from Columbia was the realization that for all future missions, starting with the first post-Columbia RTF mission (STS-114 in July 2005), NASA Headquarters managers would need to discipline themselves to maintaining a close situational awareness for all mission events. Maintaining situational awareness would keep the entire team aware of problems as they developed and perhaps give time to work problems

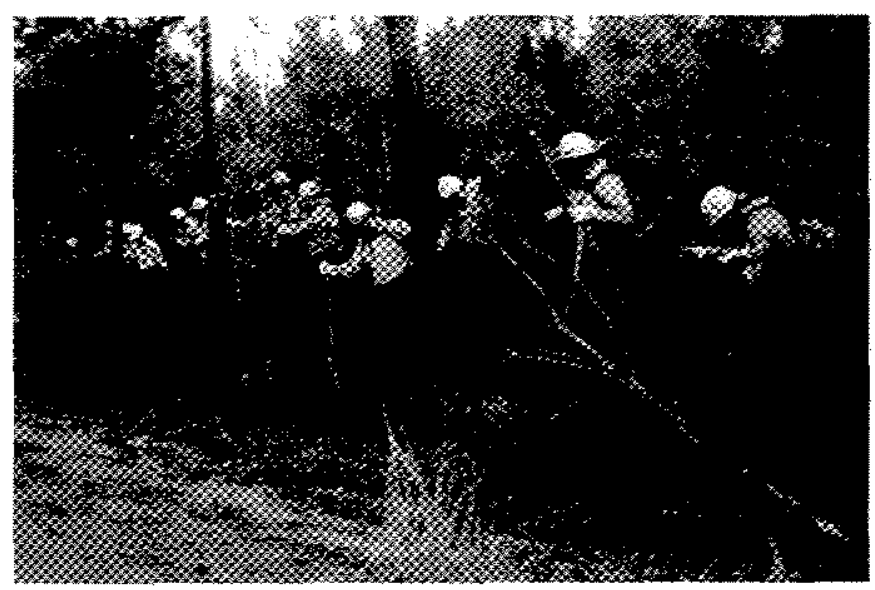

Figure 3. U.S. Forest Service Employees Search for Orbiter Debris before they developed into mishaps.

To facilitate situational awareness at Headquarters, NASA created the SOC. From an operational standpoint, Headquarters was transitioning from a strategic oversight role to an operational tactical role. The capabilities and operation of the SOC are discussed in detail in Section IV of this paper.

3. Independence of the Standing Interagency Mishap Investigation Board

Another lesson had to do with the perceived independence of the Standing Interagency Mishap Investigation Board. During and post-Columbia, there were debates about whether or not the CAIB was a truly "independent" board. At issue early on was the use of NASA's Chief of Safety and the NASA Chief Engineer as an Ex-Officio Board member and Executive Secretary, respectively. The intent of the CAP in assigning these roles was to assist the Board members with using NASA procedures to conduct the investigation. Shortly after the CAIB convened, the Chief of Safety removed himself as an Ex-Officio Board member due to a perceived conflict of interest. Later, the Board was allowed to develop and use its own investigation process to further help alleviate concern that the Board was not independent. The CAIB continued to follow the CAP process that showed it would report to the NASA Administrator. The CAP system of Support Staff (referred to as a Task Group in the CAP) and Advisors to the CAIB was used with minor modifications.

The Interagency Board organizational structure outlined in the CAP is shown in Fig. 4.

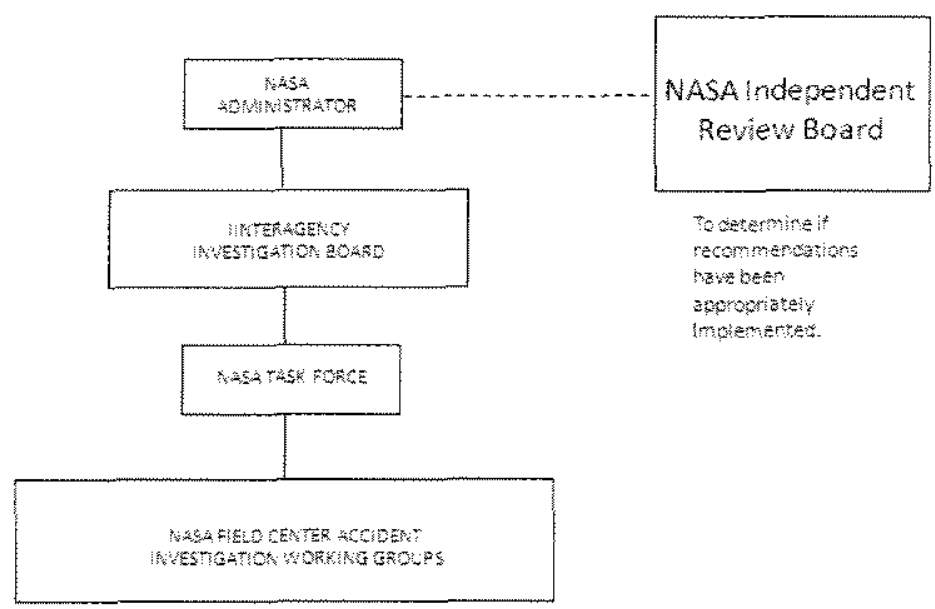

Figure 4. Standing Interagency Mishap Investigation Board and NASA Organizational Relationships

7

American Institute of Aeronautics and Astronautics 
Although most believed that the Board did a very good job of maintaining its independence, some still doubted that it could be independent given its reporting responsibility to the NASA Administrator and the large number of NASA staff that supported the Board's investigation. To "correct" this perceived flaw, a new requirement was placed in Public Law 109.155, the NASA Authorization Act of $2005^{8}$. Title VII, Subtitle B of this Law established a requirement for a Presidential Commission, called the "Human Space Flight Independent Investigation Commission", to be formed if NASA has a high visibility mishap involving loss of crew or vehicle.

The operating guidelines for the Commission would be as follows: The Commission will be established within 7 days of a mishap that results in loss of a Space Shuttle, the ISS or its operational viability, any other governmentowned U.S. space vehicle carrying humans, or a crew member or passenger of any space vehicle described above. It will investigate and determine cause; identify all contributing factors; make recommendations; and prepare a report to Congress, the President, and the public (including minority opinions and interim reports as necessary). It has the power to hold hearings and subpoena evidence, enter into contracts, and obtain assistance from other Federal Agencies as necessary. NASA employees are not allowed to serve on the Commission, except that the NASA Engineering and Safety Center will provide data and technical support as requested by the Commission.

At the time of a mishap, NASA senior management would decide whether or not NASA should conduct its own investigation, as outlined in the CAP, in parallel with the Commission investigation.

\section{The NASA Headquarters Space Operations Center (SOC)}

The NASA Headquarters SOMD has established the SOC as a focal point to support senior management before, during, and after a contingency involving SOMD missions. The SOC facility, as shown in Fig. 5, is located on the $7^{\text {th }}$ floor of the NASA Headquarters building in Washington, DC. The SOC, which was created after the Columbia accident, has supported all Space Shuttle missions since Return to Flight in 2005, as well as ongoing operations of the ISS. This section describes the capabilities of the SOC and its role in providing situational awareness for a spaceflight contingency response.

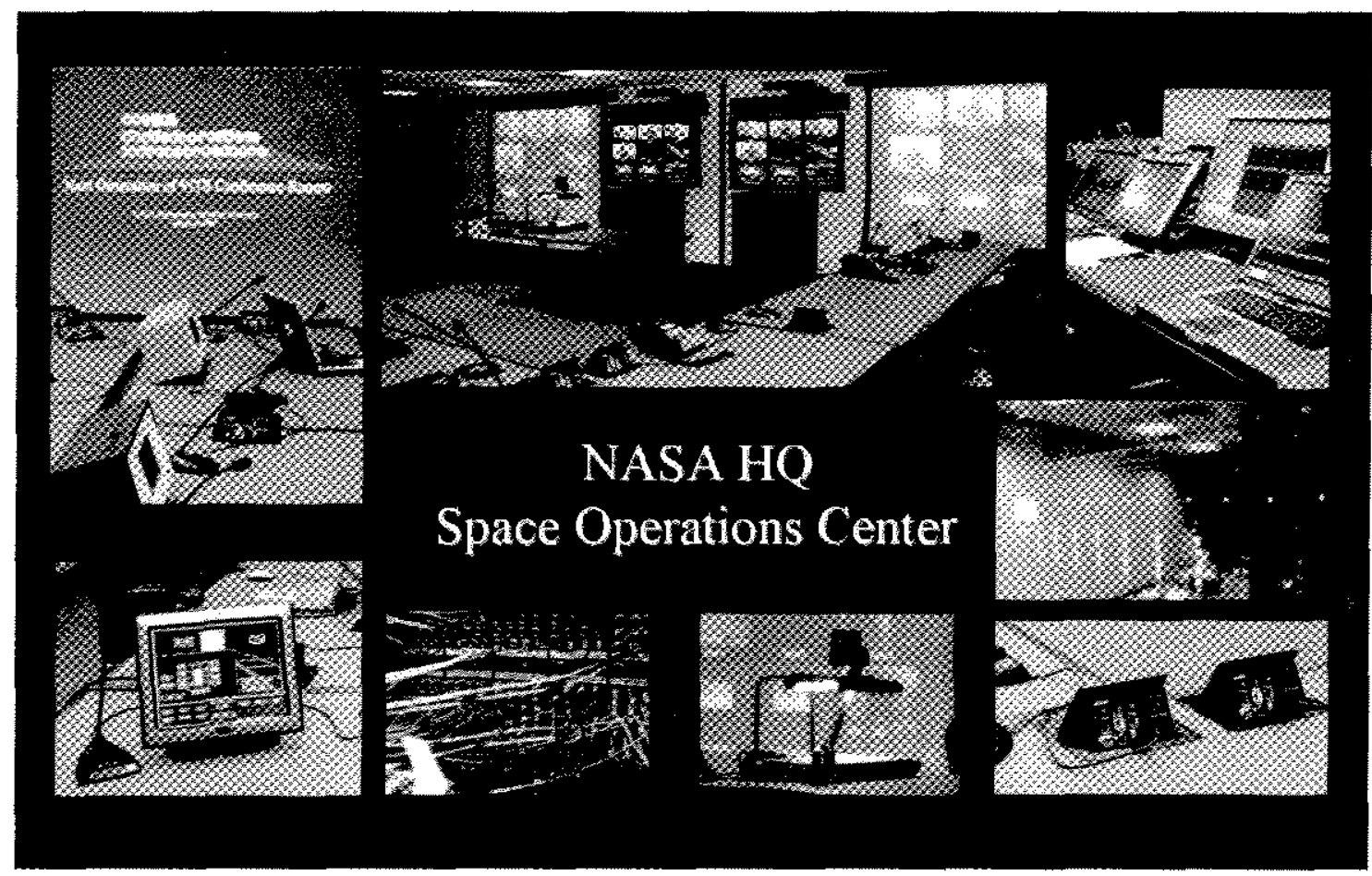

Figure 5. The NASA Headquarters Space Operations Center 
Table 1. Summary of SOC capabilities

- Controlled access facility w/motion detectors

- Dedicated room operator

- Mission voice loops (Shuttle and ISS) via NASA standard voice keysets

- HD video and audio conferencing systems

- $5 \mathrm{HD}$ room video cameras

- Five 65" HD plasma televisions

- Can display up to 19 separate video displays simultaneously

- Cable, Direct TV, HDTV, and direct feed C-Band mission TV capable

- HD video recording/playback capabilities

- Two HD projectors and fixed HD screens

- 4 camera views of realtime ISS video downlink

- Laptops and access-controlled data server

- Dedicated SOC email account

- $251 \mathrm{~GB}$ VOIP telephones (international capable)

- 50 table-top interfaces to local area networks

- 14 location time zone clocks

- Mission Elapsed Time (from NASA tracking stations) \& Mission Event clocks

- Individually controlled room speakers

- Touch screen room controllers

- External touch screens with mission and meeting information

- Access to key mission systems (e.g., SSP subsystem engineering data, Mission Control Center internet-based audio and information systems)

- In-room printer, fax machines, and document scanners

- Independent heating/AC controls

- UPS backup power

\section{A. SOC Capabilities}

The SOC provides a secure environment for receiving and displaying sufficiently detailed mission data to enable Headquarters staff to monitor and assess mission operations in real-time. SOC resources are used to provide senior Agency management with reliable and timely status and assessments of Space Shuttle and ISS mission operations. Capabilities needed to perform these functions include realtime access to mission video, data, and voice loops; video and voice conferencing capabilities; robust multimedia display capabilities; dedicated laptops and printers; secure data storage; telephones and network drops; and multiple mission/time zone clocks to support the international launch and mission operations that are monitored from the SOC. Because the $\mathrm{SOC}$ is used strictly for mission monitoring and has no actual command and control functions, there is no commanding capability. A summary of SOC capabilities is shown in Table 1 .

The SOC was designed to function as both a full featured conference room and a mission support facility. This enables Headquarters personnel to participate in routine mission meetings, such as the daily SSP and ISS Mission Management Team (MMT) meetings, where key mission decisions are made, while simultaneously monitoring mission operations. (The SOC can and has been used to allow NASA senior managers video and telephone access to crews on orbit.)

In the case of a declared spaceflight contingency, the SOC provides a secure location for senior managers to convene for mishap response meetings and to collect/disseminate information.

Two additional nearby conference rooms with limited SOC capabilities are also available as overflow or backup facilities when needed.

\section{B. Role of the SOC in Providing Routine Situational Awareness}

As was discussed in Section III of this paper, one of the key lessons learned from the Columbia accident was the need to increase the level of situational awareness prior to and during a mishap to enable a more effective and timely response. Since Columbia, the SOMD has enhanced its monitoring of critical human spaceflight events, using the SOC capabilities described above, in order to provide senior managers with routine mission status reports and contingency alerts. The SOC staff, comprised of senior SOMD personnel supporting the SSP and ISSP, performs these monitoring/reporting functions and provides the linkage between flight management teams and Headquarters senior management. The SOC staff distills pertinent technical information from a variety of detalled mission data sources (e.g., mission video, voice loops, information systems, meetings) and summarizes key points at a level appropriate to recipients of the SOC status reports.

Who is the audience for the SOC reports? In general, the audience is senior Agency leadership, other U.S. federal agencies, and NASA Headquarters/Center personnel who need to be informed of or involved in a Space Shuttle or ISS contingency response. As defined in Section II of this paper, this includes the HCAT, NASA Headquarters and Center senior management, mishap investigation board members, ISS and SSP managers, key personnel in the U.S. Government executive branch, and Headquarters personnel representing functional areas such as safety and mission assurance, engineering, public affairs, external relations, general counsel, institutional management, and legislative affairs, that would support the mishap response.

9

American Institute of Aeronautics and Astronautics 


\section{Monitoring of ISS Operations}

The SOC is not staffed on a continual basis, even though the ISS Program has ongoing crewed operations 24/7, SOC monitoring and reporting of ISS operations is reserved for certain critical mission activities, which are considered to be either inherently more risky or of much greater interest than routine daily operations. Events that are monitored include all spacewalks (also known as Extravehicular Activity (EVA)), arrivals/departures of visiting vehicles to the ISS, launches/landings of ISS crewmembers aboard Russian Soyuz spacecraft, and relocations of a Soyuz spacecraft at the ISS. ISS international partner vehicles that have visited the ISS include the Russian crewed Soyuz, and uncrewed Russian Progress, European Automated Transfer Vehicle (ATV) and Japanese H-II Transfer Vehicle (HTV) vehicles. Commercial cargo vehicles are expected to arrive in the next few years, followed by future crewed exploration vehicles. All of these events are monitored; other events may be monitored on a case-by-case basis.

Event status reports are typically just brief text messages describing progress or completion of a mission event, sent via e-mail to a pre-defined distribution list. Here is an example of a message used for the arrival of a visiting vehicle, in this case the Japanese HTV:

The Japanese H-II Transfer Vehicle \#1 (HTV-1) is on schedule for capture and berthing later this afternoon. Since its launch on September 10, the HTV-1 successfully passed a series of flight demonstrations prior to its arrival at the ISS. The vehicle is currently at a hold point 30 meters from the ISS and is scheduled to arrive at the capture point $(8.9 \mathrm{~m}$ from ISS) at approximately 3:30 pm EDT. ISS Flight Engineers Nicole Stott and Frank DeWinne will use the station robotic arm to capture HTV-1 and berth it to the Node 2 nadir port. Capture is scheduled for approximately 3:50 pm EDT. The Space Operations Center (SOC) is staffed and will monitor this event.

Here is an example of a typical status message marking the start of an ISS EVA:

ISS Commander Gennady Padalka and Flight Engineer Mike Barratt have begun tonight's spacewalk, with hatch opening at 2:55 AM EDT. The EVA is scheduled to last less than I hour. Tonight's "internal" EVA will take place within the depressurized transfer compartment between the Service Module and the Functional Cargo Block (FGB) module. The crew will relocate a docking cone to the zenith docking assembly where the Mini-Research Module 2 (MRM2) will be docked in November. The MRM2 will provide an additional docking port for Russian vehicles.

\section{Monitoring of Space Shuttle Operations}

Monitoring and reporting for Space Shuttle missions is more extensive than for standalone ISS events. In addition to realtime status reports for critical events, there are SOC Daily Reports (described below) that can be used for more detailed discussion of mission issues.

The SOC is staffed from several days before a Shuttle launch until after landing. SOC reporting begins with the results of the Launch minus 2 Day (L-2) and L-1 Mission Management Team (MMT) meetings, so that senior managers are aware of any issues that are being worked prior to launch. The SOC team also monitors the pre-launch sequence, beginning with tanking, and provides periodic status messages tracking the progress of the launch countdown, including updates to the launch weather forecast.

For each on-orbit flight day between launch and landing, the SOC team monitors mission operations and key mission meetings. A SOC Daily Report is produced which summarizes the day's major accomplishments, status of Shuttle and ISS systems, significant issues that may impact the mission, key decisions that have been made by the Shuttle and ISS MMTs, and a summary of upcoming events by flight day. The SOC Daily Report includes the current assessment of the Shuttle's Thermal Protection System (TPS), as downlinked imagery of the TPS is evaluated until the TPS is cleared for landing. An example of the SOC Daily Report is provided in Fig. 6.

Space Shuttle Landing day, like launch day, is monitored very closely with numerous status updates from deorbit prep through "Wheels Stop" at the two CONUS Shuttle landing sites: KSC in Florida or Edwards Air Force Base in California. Besides launch and landing, realtime event status messages are also sent for docking, undocking, EVAs, significant robotic operations, and other key events.

\section{Mission Briefing Packages}

Also, prior to each Space Shuttle flight and Soyuz mission to the ISS, a briefing package is distributed to the standard SOC distribution list which describes basic information about the mission and the Headquarters contingency action plan. This background information, along with the realtime mission status updates, helps to promote the situational awareness that is needed to effectively respond to a contingency situation. Management knows when critical spaceflight events are about to happen, when they are completed, and is informed of issues as they arise, so that if significant problems do occur, they are in a much better position to react. Senior managers and others within the NASA Headquarters building also know that they can come to the SOC to watch a mission event firsthand, to get a quick status, or to request additional information about a specific issue. 


\section{SOC Daily Summary for STS-127/ISS 2J/A}

Flight Day 03 (July 17, 2009)

\section{Today's Highlights Flight Day 03 (FD 03):}

- From 12:56 to 1:05 PM EDT, Endeavour successfully executed an R-Bar Pitch Maneuver, allowing Space Station personnel to photograph the Orbiter's belly Thermal Protection System (TPS)/tile. The photographs will be downlinked for analysis and the results of this TPS survey reported at an upcoming Space Shuttle Mission Management Team meeting.

- Endeavour docked with Station at 1:47 PM EDT and the hatches between the two spacecraft were opened at 3:55 PM.

- Later today, the Space Shuttle crew will begin preparations for tomorrow's first of five planned EVAs.

\section{Shuttle Status}

- All orbiter systems are performing nominally.

- Debris Analysis Team Status. The FD 2 RCC inspections were completed yesterday and all imagery was downlinked. Currently the Level 1 analysis is complete and the more detailed Level 2 analysis is approximately $67 \%$ complete. No issues have been identified so far.

- Cryo margins (above 16+0+2) are Hydrogen limited: 24 hours of "SSPTS-off" time available; 48 hours of "SSPTS-on" time available.

\section{ISS Status}

- There are currently no ISS systems that would impact docked operations.

- With today's exchange of Soyuz seatliners, Endeavour Mission Specialist Tim Kopra and Space Station Flight Engineer Koichi Wakata swap crew affiliations. Wakata has spent 124 days in space, 122 days as a space station Expedition crew member.

\section{Mission Timeline Look-Ahead (All times are Eastern Daylight Time):}

July 18 (FD 04) EVA \#1 (JEF Installation, UCCASSiPAS deploys, CETA cart mods)

- Shuttle crew wake up (7:03 AM)

- EVA\#1 Egress (12:03 PM)

- JEF Unberth/Handoff (1:43 PM)

- JEF Install (5:38 PM)

- EVA \#1 ingress (6:23 PM)

- Shuttle crew sleep (22:33 PM)

- Meetings: International Space Station MMT at 9:00 AM; Space Shuttie MMT at 2:00 PM

July 19 (FD 05) Focused Inspection (If Required), ICC-VLD Unberth

July 20 (FD 06) ICC-VLD instalf; EVA \#2 (Spares Transfer to ESP-3, JEF forward VE install)

July 21 (FD 07) Jt.E Installation \& Activation, $1 / 2$ day off, ICC-VLD Translate to Worksite 8

July 22 (FD 08) EVA \#3 (JAXA Payload Prep, P6 Battery R\&R (4))

July 23 (FD 09) JAXA Payload Transfers from JLE to JEF

Juiy 24 (FD 10) EVA \#4 (P6 Battery R\&R (2), JAXA aft VE instali), ICC-VLD Return to PLB

July 25 (FD 11) Crew Off Duty Day

July 26 (FD 12) JLE Transfer to Payload Bay

July 27 (FD 13) EVA \#5 (SPDM MLI, Z1 Patch Panel, PAS Deploys, WETA install)

July 28 (FD 14) Hatch Close, Undock, Flyaround

July 29 (FD 15) Late inspection

July 30 (FD 16) FCS Checkout, RCS Hot Fire, DRAGONSAT and ANDE-2 Deploys

July 31 (FD 17) Nominal KSC Landing (at approximately 10:45 AM EDT)

NASA Headquarters

Space Operations Center (SOC), 7D61

Figure 6. Sample SOC Daily Report from mission STS-127 / ISS - 2J/A

11

American Institute of Aeronautics and Astronautics 


\section{Role of the SOC During and After a Mishap}

In the event of a mishap affecting the Space Shuttle or ISS, those on duty in the SOC at the time of the mishap will assist as needed in initiating the appropriate response per the process defined in Section II of this paper. This may include notifying management, the HCAT, and others of the mishap. After a contingency is formally declared, the SOC facility will transition to the HCAT which will use it as the HCAT Action Center, as was done after the Columbia accident. As was noted earlier, the SOC provides a secure environment with videoconferencing capabilities that can be used for mishap response meetings and data collection.

In case of a mishap involving an ISS visiting vehicle (e.g., Progress, Soyuz, ATV, HTV), the vehicle owner (e.g., space agency of Russia, Europe, or Japan; commercial launch vehicle provider) is responsible for the mishap response and mishap investigation related to the vehicle. However, if the ISS or the ISS crew is impacted by the mishap, then the NASA SOMD contingency action plan may also be invoked.

\section{Conclusions}

Historically, NASA's SOMD CAP has provided the Agency with the policy, roles and responsibilities, and procedures documentation to effectively respond to mishaps. Lessons learned from the Challenger accident left NASA better prepared to handle a high visibility mishap and implement the CAP for the Columbia accident. The Agency response to the Columbia accident demonstrated the flexibility of the CAP and yielded new lessons for responding to future mishaps. This could lead one to believe that nothing is left to do to prepare for another possible mishap. The reality may be that there is nothing further from the truth.

As NASA continues to operate in Low Earth Orbit (LEO) and begins planning to move human exploration beyond LEO, the complexity of handling a mishap will no doubt significantly increase. A lack of recoverable hardware and delaying the start of a mishap investigation pending safe return of crew have the potential to complicate the determination of cause and sound implementing solutions. Also, NASA's increasing reliance on International Partners and commercial providers for crew and cargo transportation to the ISS could further complicate a mishap response because of the additional players involved in the process. Depending on the nature of the mishap and the vehicle(s) involved, there is a potential for multiple investigation boards to be operating simultaneously.

Finally, situational awareness of mission events, before, during, and after a mishap, is critical. Along with effective contingency planning, tools that assist decision makers in maintaining situational awareness are the best means to prepare for, and possibly even prevent, future mishaps. The NASA Headquarters Space Operations Center is one such tool.

\section{References}

1"Space Shuttle Program Contingency Review Plan," NASA Headquarters, Washington, DC, September 1980.

2"Agency Contingency Action Plan (CAP) for Space Operations", NASA Headquarters, Washington, DC, November 13, 2009.

${ }^{3}$ NASA letter(s) to Potential Interagency Board Members, June 19, 2005.

"NASA Procedural Requirements for Mishap Reporting, Investigating, and Recordkeeping," NPR 862 1.1B, May 23, 2006.

s"Columbia Accident Investigation Board Report," Volume I, August 2003, Chapter 2, pp. 42.44, URL: http:/www nasa.gov/columbia/home/CAIB Voll html.

"Columbia Accident Investigation Board Report," Volume $\quad$, August 2003, URL: http://www nasa.gov/columbia/home/CAIB Voll html

"NASA's Implementation Plan for Space Shuttle Return to Flight and Beyond," Final Edition, May 15, 2007, URL: http://www nasa gov/pdf/178101main rtfip final 200705.pdf.

${ }^{8}$ Public Law 109-155, "National Aeronautics and Space Administration Authorization Act of 2005," December 30, 2005. 